\section{CHANGES IN ARTERIAL OXYGEN TENSION CORRELATE WITH CHANGES IN END- EXPIRATORY CARBON MONOXIDE LEVEL}

Patrick Schober, $M D^{1}$, Melanie Kalmanowicz ${ }^{2}$, Lothar A. Schwarte, MD, $P h D^{1}$, Joerg Weimann, $M D^{1}$ and Stephan A. Loer, MD, PhD, $\mathrm{MSc}^{1}$

From the ${ }^{1}$ Department of Anaesthesiology, VU Medisch Centrum, PO Box 7057, 1007 MB, Amsterdam, The Netherlands.; ${ }^{2}$ Department of Anaesthesiology, Heinrich-Heine-University, Moorenstrs, 40225, Düsseldorf, Germany.

Received 16 November 2006. Accepted for publication 11 January 2007.

Address correspondence to P. Schober, Department of Anaesthesiology, VU Medisch Centrum, PO Box 7057, 1007 MB, Amsterdam, The Netherlands.

E-mail: P.Schober@vumc.nl
Schober P, Kalmanowicz M, Schwarte LA, Weimann J, Loer SA. Changes in arterial oxygen tension correlate with changes in end-expiratory carbon monoxide level.

J Clin Monit Comput 2007; 21:131-135

ABSTRACT. Objective. Carbon monoxide (CO) and oxygen compete for haemoglobin binding sites. While the effects of increased inspiratory oxygen fractions on exhaled carbon monoxide concentrations have been studied previously, the relationships between intravascular oxygen tension, blood carboxyhaemoglobin levels and expiratory $\mathrm{CO}$ concentrations remain unclear. We therefore studied the effects of increases in arterial oxygen tension as crucial determinant for the displacement of carbon monoxide from its haemoglobin bond during lung passage. Methods. Measurements of endexpiratory $\mathrm{CO}$ concentrations (eCO), arterial oxygen tensions and carboxyhaemoglobin concentrations were performed in 19 patients while breathing air and oxygen. Results. With increasing $\mathrm{PaO}_{2}$ (from $11.5 \pm 1.9$ to $35.2 \pm 10.3 \mathrm{kPa}$ ) endexpiratory $\mathrm{CO}$ concentrations increased from $8.6 \pm 4.9$ to $16.7 \pm 9.4 \mathrm{ppm}, p<0.001$, with a mean increase of $0.36 \mathrm{ppm}$ $\mathrm{CO}$ per $\mathrm{kPa}$ increase in $\mathrm{PaO}_{2} \quad(\Delta \mathrm{eCO} \quad[\mathrm{ppm}]=0.36$ $\left.\star \Delta \mathrm{PaO}_{2}[\mathrm{kPa}]\right)$. Increases of arterial oxygen tension correlated with increases of end-expiratory $\mathrm{CO}$ concentration $\left(\mathrm{r}^{2}=0.33\right)$. Arterial carboxyhaemoglobin concentrations decreased from $1.06 \pm 0.37$ during air breathing to $0.92 \pm 0.35 \%$ after 5 minutes of oxygen inhalation $(p<0.001)$. Conclusions. Oxygen-induced increases in exhaled $\mathrm{CO}$ correlate with increases in arterial oxygen tensions. Furthermore, oxygen inhalation reduces carboxyhaemoglobin levels, supporting the concept of accelerated $\mathrm{CO}$ elimination by oxygen via the lungs.

KEY WORDS. Carbon monoxide, oxygen, haemoglobin.

\section{INTRODUCTION}

In recent years, endogenous carbon monoxide (CO) production has been shown to play a critical role during inflammatory processes [1-4]. In line with this, exhaled $\mathrm{CO}$ has been found to be increased in critically ill patients [5-7], and thus may be used as a diagnostic or monitoring tool. We and others have previously shown that high inspired oxygen concentrations, that are often used during mechanical ventilation in these patients, increase exhaled $\mathrm{CO}$ concentrations $[8,9]$ and may therefore interfere with exhaled CO measurements. Since oxygen and CO compete for identical haemoglobin binding sites [10] and this competition occurs in the vascular rather than the alveolar compartment, we hypothesize that the oxygen-induced displacement of CO from haemoglobin largely depends 
on pulmonary capillary rather than alveolar oxygen tension. Pulmonary capillary oxygen tension is inaccessible to clinical measurements and arterial oxygen tension $\left(\mathrm{PaO}_{2}\right)$ is often used as a surrogate. However, especially in the critically ill, $\mathrm{PaO}_{2}$ may not be predicted from $\mathrm{FiO}_{2}$ due to altered gas diffusion through the alveolo-capillary membrane and widely scattered ventilation-perfusion ratios as part of inflammatory pulmonary diseases. Therefore, this study in 19 patients scheduled for cardiac surgery was based on the hypothesis that $\mathrm{PaO}_{2}$ rather than the $\mathrm{FiO}_{2}$ may correlate with exhaled $\mathrm{CO}$ levels.

\section{METHODS AND MATERIALS}

After approval by the Institutional Review Board and informed consent, patients scheduled for cardiac surgery $(n=19$, Table 1$)$ were routinely instrumented preoperatively with arterial lines. Among the patients were two current smokers who were abstinent for more than 12 hours prior to surgery.

\section{Measurements}

End-expiratory $\mathrm{CO}$ (eCO in parts per million, ppm) concentrations were measured with an electrochemical analyzer (microPac, Dräger, Lübeck, Germany) with a sampling rate of $0.5 \mathrm{~Hz}$. According to the manufacturer's specifications $\mathrm{CO}$ is measured in a range from 0 to $400 \mathrm{ppm}$ with a reproducibility of (3\%). In order to obtain samples of end-expiratory gas at room air patients were asked to exhale slowly from total lung capacity to expiratory reserve volume over a period of approximately 20 seconds into a disposable mouthpiece connected to the analyzer via a $30 \mathrm{~cm}$ hose. At the end of expiration gas flow ceased and the end-expiratory gas remaining in the hose (volume $5.9 \mathrm{ml}$ ) served as the sample for determination of alveolar $\mathrm{CO}$ concentrations. Technical aspects of the measurements including time-course and reproducibility have been described in detail previously and we

Table 1. Demographic data (mean $\pm S D)$.

\begin{tabular}{ll}
\hline Gender (female/male) & 3 female/16 male \\
\hline Age (years) & $69.9 \pm 7.5$ \\
Height $(\mathrm{cm})$ & $171.5 \pm 8.5$ \\
Weight $(\mathrm{kg})$ & $83.3 \pm 12.7$ \\
Baseline haemoglobin $\left(\mathrm{g} \mathrm{dl}^{-1}\right)$ & $12.1 \pm 1.3$ \\
Baseline arterial $\mathrm{P}_{\mathrm{a}} \mathrm{O}_{2}(\mathrm{kPa})$ & $11.5 \pm 1.9$ \\
Baseline arterial $\mathrm{P}_{\mathrm{a}} \mathrm{CO}_{2}(\mathrm{kPa})$ & $5.1 \pm 0.5$ \\
\hline
\end{tabular}

have shown that a stable alveolar plateau is reached during expiration [8]. This plateau value was defined as endexpiratory carbon monoxide concentration.

All measurements were performed in a non-smoking area (operating theatre). Before each measurement, ambient CO levels as well as $\mathrm{CO}$ concentrations within the oxygen reservoir were measured to exclude exogenous CO sources.

Arterial oxygen tension $\left(\mathrm{PaO}_{2}\right)$ and arterial carboxyhaemoglobin levels $(\mathrm{CO}-\mathrm{Hb})$ were measured using a standard clinical blood gas analyzer (ABL 725, Radiometer, Copenhagen, Denmark).

\section{Study protocol}

Baseline measurements of eCO, $\mathrm{PaO}_{2}, \mathrm{CO}-\mathrm{Hb}$ were performed after patients have been rested for 10 minutes in a supine position. Subsequently, patients breathed oxygen via a tightly fitting face mask for 5 minutes until expiratory oxygen fraction was above 0.9 in all patients excluding dilution of alveolar gas by residual nitrogen. Then, all measurements were repeated as described above.

\section{Statistics}

Data are presented as mean \pm standard deviation. Differences between values obtained during air and oxygen breathing were analyzed by two-tailed, paired $t$-test (Prism 4.0 statistical package, GraphPad Software, San Diego, CA, USA). Correlations were calculated using Pearson's correlation coefficient $\left(\mathrm{r}^{2}\right)$. A $p<0.05$ was considered statistically significant.

\section{RESULTS}

Oxygen inhalation resulted in an increase in $\mathrm{PaO}_{2}$ from $11.5 \pm 1.9$ to $35.2 \pm 10.3 \mathrm{kPa}(p<0.001$, Figure $1 \mathrm{a})$, as well as an increase in eCO levels from 8.6 \pm 4.9 to $16.7 \pm 9.4 \mathrm{ppm}(p<0.001$, Figure 1b). As shown in Figure 2 the increase in $\mathrm{PaO}_{2}$ was associated with an increase in eCO in all patients with exception of one patient in which eCO levels remained constant. The mean increase in eCO per increase in $\mathrm{PaO}_{2}\left(\Delta \mathrm{eCO} / \Delta \mathrm{PaO}_{2}\right)$ was $0.36 \pm 0.28 \mathrm{ppm} / \mathrm{kPa}$ with a significant correlation between these two parameters $\left(\mathrm{r}^{2}=0.33, p<0.01\right)$. Moreover, while eCO increased, arterial carboxyhaemoglobin concentrations decreased from baseline values of $1.06 \pm 0.37$ during air breathing to $0.92 \pm 0.35 \%$ while inhalation of oxygen $(p<0.001$, Figure 3$)$. ECO concentrations did not correlate with arterial carboxyhaemoglobin concentrations $(P=0.83)$. 

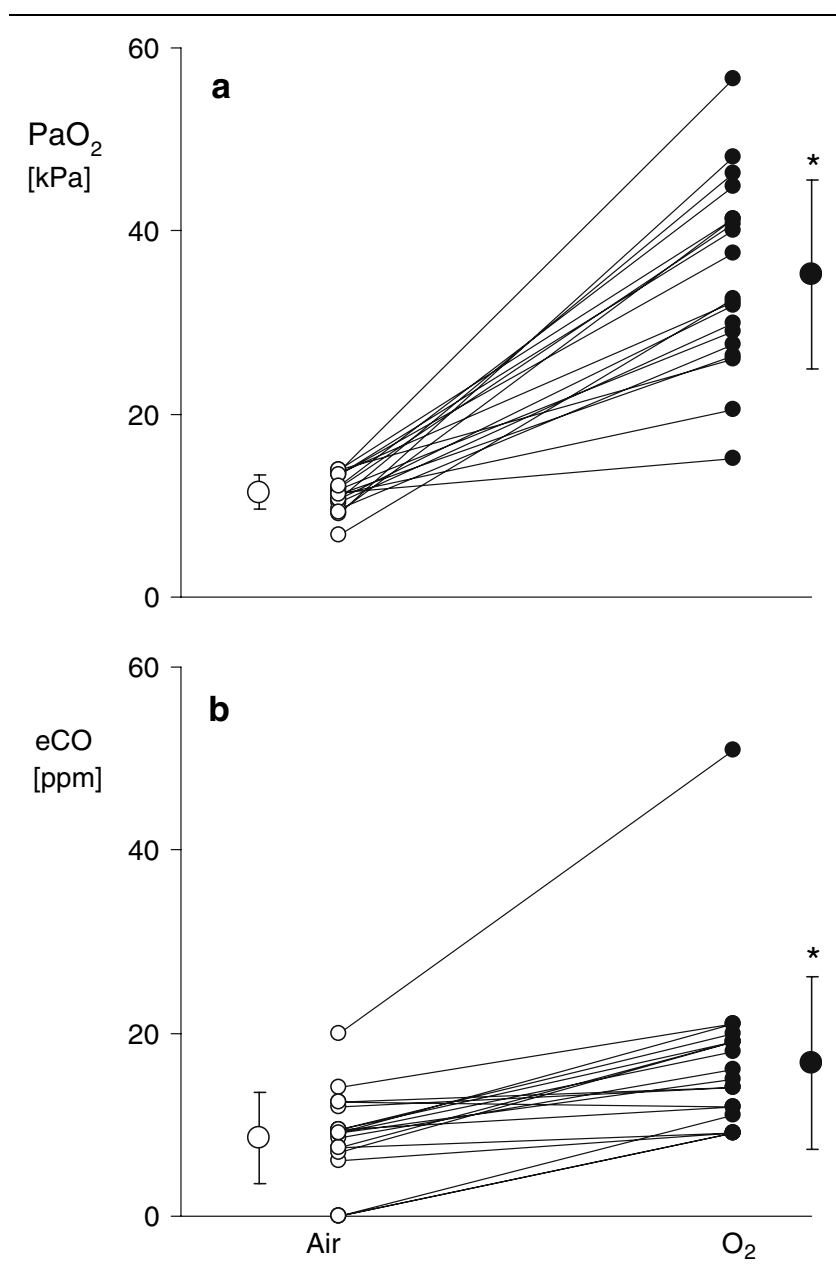

Fig. 1. Arterial oxygen tensions $\left(\mathrm{PaO}_{2}\right.$, Figure 1a) and end-expiratory carbon monoxide concentrations (eCO, Figure 1b) of patients $(n=19$, individual values and mean $\pm S D, *<0.001)$ while breathing air (open circles) and oxygen (closed circles). Open and closed circles representing the same patient are connected by a line.

\section{DISCUSSION}

Exhaled carbon monoxide originates from exogenous (ambient CO) and endogenous sources. Endogenous CO production is mainly due to degradation of haeme and the first and rate-limiting step of this metabolic pathway is catalyzed by microsomal haeme oxygenase $[1-3,11]$. Of the three known isoforms, haeme oxygenase- 1 is inducible by oxidative stress and, therefore, elevated exhaled carbon monoxide levels were suggested to be a noninvasive marker of local airway and systemic inflammation [5-7, 12-15]. Moreover, elevated expiratory CO concentrations may be of diagnostic value in patients with suspected carbon monoxide intoxication [16]. Since critically ill patients as well as patients with inflammation or intoxication are often treated with oxygen, awareness

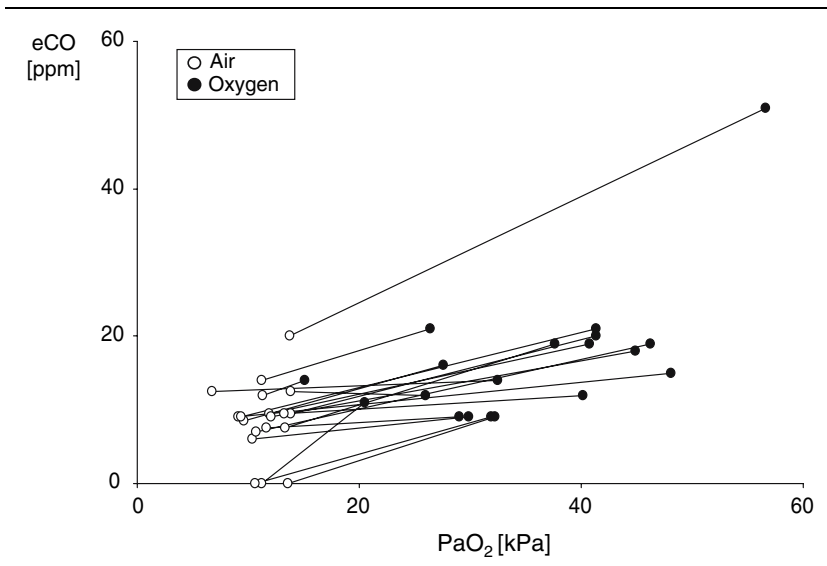

Fig. 2. Arterial oxygen tension $\left(\mathrm{PaO}_{2}\right)$ and corresponding end-expiratory carbon monoxide concentration (eCO) of patients $(n=19)$ while breathing air (open circles) and oxygen (closed circles). Open and closed circles representing the same patient are connected by a line. The mean slope corresponding to the mean increase in end-expiratory $\mathrm{CO}$ concentration per $\mathrm{kPa}$ increase in $\mathrm{PaO} 2\left(\mathrm{\Delta eCO} / \Delta \mathrm{PaO}_{2}\right)$ is 0.36 .

of effects of oxygen inhalation on expiratory and blood $\mathrm{CO}$ concentrations may be helpful in the interpretation of the obtained measurements.

We measured exhaled carbon monoxide concentrations in patients in supine position breathing room air or oxygen. $\mathrm{CO}$ concentrations were quantified with an electrochemical analyzer as described previously [8]. The last portions of the exhaled gas represented samples of alveolar air and were defined as endexpiratory $\mathrm{CO}$ concentrations. All measurements were performed in a non-smoking area. In addition, we determined CO concentrations in the ambient air to ensure that all measured CO represented endogenous carbon monoxide of the patients. During inhalation of oxygen, we measured

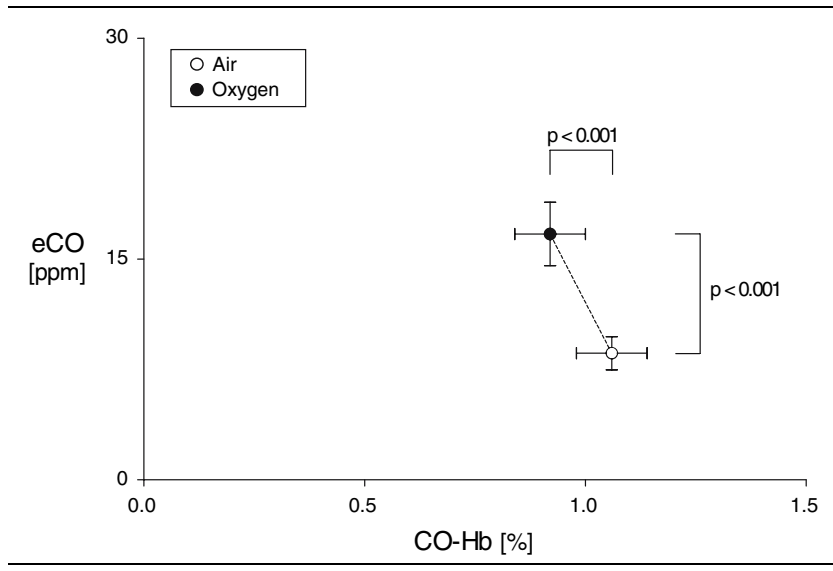

Fig. 3. Arterial carboxyhaemoglobin $(\mathrm{CO}-\mathrm{Hb})$ and end-expiratory carbon monoxide concentration (eCO) of patients $(n=19$, mean $\pm S E M)$ while breathing air (open circles) and oxygen (closed circles). 
in- as well as expiratory oxygen concentrations to exclude that the alveolar gas was diluted by residual or co-inspired nitrogen. Endexpiratory oxygen fractions corresponding to alveolar fractions were above 0.9 in all patients.

It is well established that oxygen competes with $\mathrm{CO}$ for the same haemoglobin binding sites, which is the basis for treating $\mathrm{CO}$ intoxications by inhalation of high oxygen concentrations. Indeed, we and others have recently demonstrated that increases in inspiratory oxygen fractions are associated with an increase in exhaled CO levels [8, 9]. However, this may only be valid for lung regions with a normal pulmonary gas exchange through the alveolarcapillary membrane, i.e. a ventilation-to-perfusion ratio close to 1 . Accordingly, ventilation-perfusion mismatch, as it occurs during lung diseases such as COPD (increased dead-space ventilation) or the acute respiratory distress syndrome (increased intrapulmonary shunting), may result in both impaired oxygen uptake and $\mathrm{CO}$ excretion through the lungs. Therefore, we hypothesized that increases in exhaled CO levels may correlate with increases in arterial oxygen tensions $\left(\mathrm{PaO}_{2}\right)$. Indeed, breathing oxygen through a tightly fitted face mask caused an increase in $\mathrm{PaO}_{2}$ in all patients. On the basis of a wide range of oxygen-induced changes in $\mathrm{PaO}_{2}(3.7$ to $42.8 \mathrm{kPa})$ in our patients, we found that increases in $\mathrm{PaO}_{2}$ significantly correlated with increases in eCO. Moreover, we demonstrated oxygen inhalation to reduce $\mathrm{CO}-\mathrm{Hb}$ levels, supporting the concept of accelerated CO elimination by oxygen via the lungs. In accordance to our findings, Weaver et al. observed in a retrospective analysis in patients an inverse correlation between arterial oxygen tension and carboxyhaemoglobin half-life and thus increased elimination [17]. However, Weaver et al. studied changes in blood $\mathrm{CO}$ levels during continuous $\mathrm{O}_{2}$ breathing, not during acute $\mathrm{PaO}_{2}$ changes. Our study aimed to investigate the relationship between acute changes in $\mathrm{PaO}_{2}$ and changes in endexpiratory $\mathrm{CO}$ concentration. To the best of our knowledge, the data show for the first time prospectively a correlation between $\Delta \mathrm{eCO}$ and $\Delta \mathrm{PaO}_{2}$. While our data suggest that eCO levels obtained in acutely ill patients receiving oxygen therapy may be erroneously high because of a high $\mathrm{PaO}_{2}$ it must be emphasized that these data only apply to acute changes of $\mathrm{PaO}_{2}$. However, patients may be treated with higher inspiratory oxygen concentrations for a longer period of time and it seems unlikely that acute eCO changes in this study can reliably represent stable eCO levels during hours of oxygen therapy. Thus our data may only serve as a qualitative advisory but do not allow estimations of $\mathrm{PaO}_{2}$-adjusted eCO concentrations. Moreover, we did not find a correlation between eCO concentrations and arterial $\mathrm{CO}-\mathrm{Hb}$ levels, so that $\mathrm{CO}-\mathrm{Hb}$ concentrations may not be estimated from eCO concentrations. Further work is needed to determine the value of measuring eCO in acutely ill patients, and/or CO intoxicated patients, and the best procedures for these clinical scenarios.

In summary, our study demonstrates that oxygen-induced increases in exhaled CO correlate with increases in arterial oxygen tensions. This is likely explained by an accelerated carbon monoxide elimination during lung passage.

\section{REFERENCES}

1. Otterbein LE, Choi AM. Heme oxygenase: colors of defense against cellular stress. Am J Physiol Lung Cell Mol Physiol 2000; 279: L1029-L1037.

2. Otterbein LE. Carbon monoxide: innovative anti-inflammatory properties of an age-old gas molecule. Antioxid Redox Signal 2002; 4: 309-319.

3. Ryter SW, Otterbein LE. Carbon monoxide in biology and medicine. Bioessays 2004; 26: 270-280.

4. Schober P, Koch A, Zacharowski K, Loer SA. Kohlenmonoxid: toxisches Molekül mit antiinflammatorischen und zytoprotektiven Eigenschaften. Anasthesiol Intensivmed Notfallmed Schmerzther 2006; 41: 140-149.

5. Morimatsu H, Takahashi T, Maeshima K, Inoue K, Kawakami T, Shimizu H, Takeuchi M, Yokoyama M, Katayama H, Morita K. Increased heme catabolism in critically ill patients: correlation among exhaled carbon monoxide, arterial carboxyhemoglobin and serum bilirubin IX $\alpha$ concentrations. Am J Physiol Lung Cell Mol Physiol 2005; 290: L114-L119.

6. Scharte M, Bone HG, Van Aken H, Meyer J. Increased carbon monoxide in exhaled air of critically ill patients. Biochem Biophys Res Commun 2000; 267: 423-426.

7. Zegdi R, Perrin D, Burdin M, Boiteau R, Tenaillon A. Increased endogenous carbon monoxide production in severe sepsis. Intensive Care Med 2002; 28: 793-796.

8. Schober P, Kalmanowicz M, Loer SA. Effects of inspiratory oxygen concentration on endtidal carbon monoxide concentration. J Clin Monit Comput 2006; 20: 89-94.

9. Zegdi R, Caid R, Van De Louw A, Perrin D, Burdin M, Boiteau R, Tenaillon A. Exhaled carbon monoxide in mechanically ventilated critically ill patients: influence of inspired oxygen fraction. Intensive Care Med 2000; 26: 12281231.

10. Di Cera E, Doyle ML, Connelly PR, Gill SJ. Carbon monoxide binding to human hemoglobin $\mathrm{A}_{0}$. Biochemistry 1987; 26: 6494-6502.

11. Ryter SW, Otterbein LE, Morse D, Choi AM. Heme oxygenase/carbon monoxide signaling pathways: regulation and functional significance. Mol Cell Biochem 2002; 234-235: 249-263.

12. Biernacki WA, Kharitonov SA, Barnes PJ. Exhaled carbon monoxide in patients with lower respiratory tract infection. Respir Med 2001; 95: 1003-1005.

13. Horvath I, Donnelly LE, Kiss A, Paredi P, Kharitonov SA, Barnes PJ. Raised levels of exhaled carbon monoxide are associated with an increased expression of heme oxygenase- 1 in 
airway macrophages in asthma: a new marker of oxidative stress. Thorax 1998; 53: 668-672.

14. Yamaya M, Sekizawa K, Ishizuka S, Monma M, Mizuta K, Sasaki H. Increased carbon monoxide in exhaled air of subjects with upper respiratory tract infections. Am J Respir Crit Care Med 1998; 158: 311-314.

15. Zayasu K, Sekizawa K, Okinaga S, Yamaya M, Ohrui T, Sasaki H. Increased carbon monoxide in exhaled air of asthmatic patients. Am J Respir Crit Care Med 1997; 156: 1140-1143.
16. Ernst A, Zibrak JD. Carbon monoxide poisoning. N Engl J Med 1998; 339: 1603-1608.

17. Weaver LK, Howe S, Hopkins R, Chan KJ. Carboxyhemoglobin half-life in carbon monoxide-poisoned patients treated with $100 \%$ oxygen at atmospheric pressure. Chest 2000; 117: 801-808. 